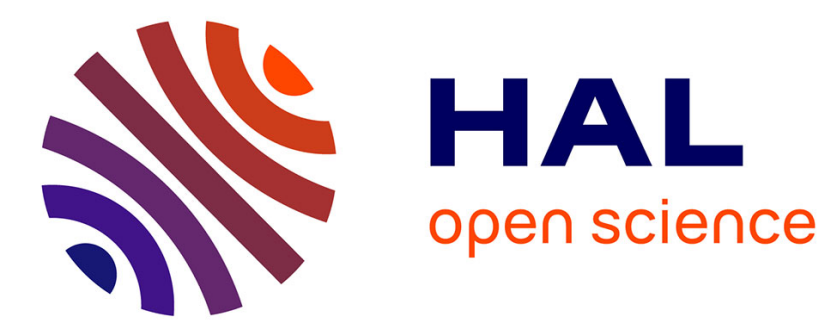

\title{
Optical spectroscopy techniques can accurately distinguish benign and malignant renal tumours.
}

Jean-Philippe Couapel, Lotfi Senhadji, Nathalie Rioux-Leclercq, Grégory

Verhoest, Olivier Lavastre, Renaud de Crevoisier, Karim Bensalah

\section{To cite this version:}

Jean-Philippe Couapel, Lotfi Senhadji, Nathalie Rioux-Leclercq, Grégory Verhoest, Olivier Lavastre, et al.. Optical spectroscopy techniques can accurately distinguish benign and malignant renal tumours.. BJU International, 2013, 111 (6), pp.865-71. 10.1111/j.1464-410X.2012.11369.x . inserm00727758

\section{HAL Id: inserm-00727758 https://www.hal.inserm.fr/inserm-00727758}

Submitted on 1 Sep 2013

HAL is a multi-disciplinary open access archive for the deposit and dissemination of scientific research documents, whether they are published or not. The documents may come from teaching and research institutions in France or abroad, or from public or private research centers.
L'archive ouverte pluridisciplinaire HAL, est destinée au dépôt et à la diffusion de documents scientifiques de niveau recherche, publiés ou non, émanant des établissements d'enseignement et de recherche français ou étrangers, des laboratoires publics ou privés. 


\section{Optical spectroscopy techniques can accurately distinguish benign and malignant renal tumours}

Jean-Philippe Couapel ${ }^{1,2,3}$, Lotfi Senhadji ${ }^{1,2}$, Nathalie Rioux-Leclercq ${ }^{4}$, Grégory Verhoest ${ }^{3}$, Olivier Lavastre $^{5}$, Renaud de Crevoisier ${ }^{1,2,6}$ and Karim Bensalah ${ }^{1,2,3}$

1 Inserm, U1099, Rennes, France

2 Université de Rennes1, LTSI, Rennes, France

3 CHU Rennes, Department of Urology, Rennes, France

4 CHU Rennes, Department of Pathology, Rennes, France

5 Université de Rennes1, IETR, UMR CNRS 6164, ProCaDec, Rennes, France

6 Centre Eugène Marquis, Department of Radiotherapy, Rennes, France

\section{INTRODUCTION}

RCC is the third most common urological malignancy after prostate and bladder cancer [1]. Because of the widespread use of abdominal imaging, its incidence has increased over the last 20 years. Still, the natural evolution of RCC is sometimes difficult to predict, and up to $25 \%$ of patients with a localized tumour at diagnosis will develop metastases [2]. Various biomarkers have been suggested to have a prognostic value to foretell the course of RCC but to date none is used in clinical practice. It is therefore interesting to consider new approaches to RCC.

Optical spectroscopy (OS) is a group of novel technologies that are based on the interaction of light with tissue. Raman spectroscopy (RS) and optical reflectance spectroscopy (ORS) are the most commonly used OS techniques. RS uses a laser beam and ORS uses a simple white-light source. OS provides optical spectra that give information on the composition of the tissue and can therefore be described as an 'optical biopsy tool'. It has been proven that OS could precisely differentiate histological subtype and/or grade of various solid tumours including prostate [3], bladder [4] and kidney [5-8] cancers.

In the present study, we prospectively evaluated the ability of RS and ORS to differentiate benign and malignant renal tumours as well as histological subtypes among RCCs.

\section{MATERIALS AND METHODS}

Our method of RS acquisition has been described previously [5,9]. Briefly, the RS system comprised three major elements: (i) A high powered near-infrared laser (Invictus NIR laser $785 \mathrm{~nm}, 500 \mathrm{~mW}$, Kaiser Optical Systems, Ann Arbor, MI, USA), (ii) A fibre optic magnetic resonance probe, (iii) A RXN1 Raman analyser (Kaiser Optical Systems), and (iv) A laptop computer with HoloGRAMS (c) 4.1 software for Raman spectra acquisition.

The ORS system included: (i) a deuterium tungsten light source emitting light in the wavelength range of 200 to $2000 \mathrm{~nm}$, (ii) a fibre optic array probe, (iii) a 200 to $1100 \mathrm{~nm}$ USB2000 
spectrophotometer (Ocean Optics, Dunedin, FL, USA), (iv) A laptop computer with SpectraSuite (C) software (Ocean Optics).

After approval by our Institutional Review Board, we prospectively collected RS and ORS spectra in consecutive kidney specimens removed due to the suspicion of cancer. Between March and October 2011, 64 operations were performed, including 37 radical nephrectomies and 27 partial nephrectomies. Four patients were excluded based on final histology results: one with liposarcoma, one with an Xp11 translocation RCC, one with a mixed epithelial and stromal tumour, and one with a totally necrotic tumour. Surgery was completed through an open access in 16 patients and laparoscopically (with or without robotic assistance) in 44 patients. Immediately after extraction, the specimens were stored on ice and transferred to the pathology department. Spectra were acquired $\leq$ 15 min of extraction.

For RS, we used the same parameters as in our previous experiments $[5,9]$ : laser beam was set at $50 \mathrm{~mW}$ and focused on a $500 \mu \mathrm{m}$ spot on the surface of the sample. Acquisition period was $30 \mathrm{~s}$. A wavelength of $785 \mathrm{~nm}$ was chosen to minimise background autofluorescence due to natural fluorophores.

For ORS, before each session of measurements, we acquired a calibration spectrum from a standard surface. This standard surface provides $\approx 100 \%$ of reflectance in the wavelength range of $250-$ $1000 \mathrm{~nm}$. We also recorded a background measurement with the same experimental setting but with the light source turned off. This background data was subtracted from each optical measurement during data analysis. The acquisition period was 10 s.

RS and ORS spectra were acquired in a complete dark environment to avoid artefacts due to ambient light (Fig. 1). After longitudinal sectioning of the specimens by the pathologist, areas without necrosis or blood clots were selected for optical acquisition. Spectra were obtained in several locations inside and on the surface of normal and tumour tissue. We obtained a total of 787 spectra (419 RS and 368 ORS).

We used the same statistical method for RS and ORS spectra. Analysis of the signal comprised four steps:

(i) Normalisation of the signal by dividing every spectral point by the area under the curve to ensure all spectra were comparable. All spectra were of optimal quality.

(ii) Initial ( $\lambda<150 \mathrm{~cm}^{-1}$ in RS and $\lambda<250 \mathrm{~nm}$ in ORS) and final ( $\lambda>830 \mathrm{~nm}$ in ORS) portions of the spectra were removed to avoid artefacts. Samples of benign and malignant spectra are shown in Figure 2.

(iii) Our objective was to establish a classification tool that could recognize (i) benign and malignant tumours, (ii) histological subtype of malignant tumours (i.e. clear cell, papillary and chromophobe), and (iii) chromophobe and benign tumours. For that purpose, we built a support vector machine (SVM). A SVM is a mathematical tool that allows selecting relevant features for classifying a dataset into two groups [10]. After training, the SVM is tested with a leave-one-out cross-validation technique (Fig. 3): for every classification, all spectra but one are used to train the SVM and the remaining spectrum is set aside for final testing [8]. The process was repeated with alternation of the testing spectrum for all spectra. At the end of thetest, a cross -validation score that represents the 
ability of a single spectrum to classify the assessed biological sample was obtained. We trained the SVM in the entire population and in the subset of patients with small renal tumours $(<4 \mathrm{~cm})$, as it is in this group that being able to diagnose a benign tumour is most useful in clinical practice.

(iv) A uniform and independent random integer number generator function was used in association with the SVM when there was a discrepancy between the sample numbers of spectra. For example, we had many more malignant than benign spectra (193 vs 33, respectively); randomisation process allowed the comparison of an equal number of 33 benign and malignant spectra. The process was repeated 10 times. The risk of over- or under-training of the SVM was thus limited.

\section{RESULTS}

The clinicopathological characteristics of the population are given in Tables 1 and 2. Histology was malignant in 53 cases (41 clear-cell, eight papillary, and four chromophobe tumours), and benign in seven cases (four oncocytomas, two angiomyolipomas, and a haemorrhagic cyst).

Classification scores are presented in Tables 3 and 4. Overall, the SVM could differentiate benign from malignant renal tumours with an accuracy of $96 \%$ (RS) and $88 \%$ (ORS). In the subset of malignant tumours, the SVM was able to correctly recognise clear-cell carcinomas $88 \%$ and $89 \%$ of the times with RS and ORS, respectively. The SVM could set apart chromophobe carcinomas and benign lesions with an accuracy of $96 \%$ (RS) and $98.4 \%$ (ORS).

When focusing on patients with small renal tumours, the ability of the SVM to differentiate benign from malignant lesions was $93 \%$ and $95 \%$ for RS and ORS, respectively. Clear-cell carcinomas could be identified with $85 \%$ and $94.7 \%$ accuracies with RS and ORS, respectively. Chromophobe carcinomas and benign tumours could be discriminated by the SVM in $87 \%$ and $99.6 \%$ of the cases, with RS and ORS respectively.

\section{DISCUSSION}

OS techniques rely on the interaction of light with tissues. RS is based on the inelastic scattering of light: when photons hit a tissue, their energy raises the molecules' vibrational state. When a molecule returns to its background level, one photon out of $10^{8}$ is emitted at a different wavelength from the incident light. This change in wavelength is known as the 'Raman shift '. ORS is based on differences of absorption of light depending on its wavelength. The analysis of RS and ORS spectra provides information on the composition and structure of a tissue. RS and ORS showed promising results for ex vivo evaluation of several solid tumours [11 - 15]. More recently, spectroscopic techniques have been used to assess urological tumours [3-8,16-22]. For example, it has been shown that RS could accurately identify bladder tumour stage and grade $[4,19,21,22]$, or differentiate inflammatory, benign and malignant prostatic tissue $[3,22]$.

In the field of RCC, we previously showed that RS could accurately differentiate tumoral from normal renal tissue as well as histological subtype and tumour grade [5]. However, our number of benign spectra was too limited for the algorithm to recognise benign and malignant renal tumours. The present study, based on a significantly larger population, showed that both RS and ORS could efficiently differentiate benign from malignant renal tumours with an accuracy $>90 \%$. The sensitivity and specificity of our model were optimal (99.1\% and $95.6 \%$ for RS and ORS, respectively). The performances of RS and ORS remained excellent in the subset of small renal tumours $(<4 \mathrm{~cm})$ with 
precision rates of $93 \%$ and $95 \%$, respectively. This is particularly interesting as in clinical practice, the most challenging situation when one needs to know whether a renal tumour is benign or malignant, is in the context of small renal masses. RS and ORS could also effectively recognise histological subtypes of malignant tumours with precision rates ranging between $80 \%$ and $93 \%$.

We specifically focused on the ability of OS techniques to discern chromophobe tumours from benign lesions. Chromophobe carcinoma accounts for $5 \%$ of malignant RCC and is generally thought to have a rather indolent profile compared with clear-cell tumours [23]. Overlapping morphological characteristics often make it difficult to differentiate chromophobe carcinoma from renal oncocytoma [24]. Moreover chromophobe carcinoma can coexists with oncocytoma inside of a hybrid tumour [25]. Diagnosis of a hybrid tumour can be challenging particularly when made on a percutaneous biopsy $[26,27]$. The present results showed that the SVM could precisely differentiate chromophobe carcinomas from benign lesions with an accuracy $>95 \%$.

The data concerning OS is rapidly growing. However, reports on urological tumours are still limited [3 $-5,8,19,21,22]$. There has been an extensive research in oncology to better appraise the natural course of cancer. Many biomarkers in the blood, genes and elsewhere have been investigated [28], but none has proven enough reliability and reproducibility to be used in clinical practice In this situation, OS is a promising technique with many potential advantages: (i) It gives immediate results (ii) It is an objective method using robust algorithms that does not need human interpretation, i(ii) It is not invasive, and (iv) It is not toxic and can easily be transferred to human care.

There have been several publications that specifically addressed the interest of OS to evaluate RCC. The team from the University of Texas showed that ORS could accurately discriminate normal and tumoral renal tissue at surgery [7]. We previously reported in a series of 36 patients that RS could differentiate normal and tumoral renal tissue, high- and low-grade tumours, as well as histological subtype of RCC $[5,8]$. In the present study, we focused on optical differences of benign and malignant renal tumours. It comprises more patients than our previous experiment with a significant number of benign lesions (seven of 60). Moreover, we refined our technique of optical acquisition by using a completely sealed black box to avoid artefacts due to ambient light.

We used two OS techniques (RS and ORS) that complement each other. RS requires heavy equipment but provides spectra with very rich information. Each molecule has its own pattern of vibration that can serve as a 'Raman biomarker'. RS would therefore be a promising method to assist the pathologist for improving diagnostic accuracy. It is well known, for example, that the establishment of Fuhrman grade is subject to intra- and inter-observer variability [29] . There have been recent reports of computational programs that could outperform human pathologists in distinguishing between grades of breast cancers and provide a more accurate prognosis than a human pathologist could manage [30] . Conversely, ORS is a simpler, cheaper and less bulky system that would be ideal for use in the operating room to help the surgeon in real-time to differentiate between a malignant and benign tumour.

The present study has several limitations. Our population, although extended, remains quite small. Optical measurements were acquired in an ex vivo environment, so the impact of blood flow has not been taken into account. Haemoglobin is the preponderant chromophore and has a high capacity to absorb light. For this reason there is a need for in vivo studies. For now, both Raman and reflectance probes are not approved for human use. We are therefore working on a specific thin probe that 
could be directly applied on the tumour surface (in case of open surgery) or inserted through a trocar (during laparoscopy) and provide optical information in real-time. We also plan to make optical measurements of frozen tissues stored in a tumour database to delineate optical features predictors of survival. Finally, comparing traditional histological interpretation to optical measurements would also be an interesting issue. We are therefore planning to compare spectra acquired from renal tumour core biopsies with the 'blinded' interpretation of an experienced uropathologist to see whether the objective information provided by OS can help reduce the $10 \%$ uncertainty usually associated with renal biopsy analysis.

In conclusion, the present study showed that a combination of OS techniques with the help of appropriate signal processing approaches could accurately distinguish between benign and malignant renal tumours ex vivo. These results support recent publications to consider OS as a promising tool for the evaluation of kidney tumours.

\section{ACKNOWLEDGEMENTS}

Funding/Support and role of the sponsor: Association pour la Recherche Contre le Cancer (ARC) and Association Française d'Urologie (AFU).

\section{CONFLICT OF INTEREST}

None declared.

\section{REFERENCES}

1 Pantuck AJ, Zisman A, Belldegrun AS. The changing natural history of renal cell carcinoma. J Urol 2001; 166:1611-23

2 Ravaud $\mathrm{A}$, Wallerand $\mathrm{H}$, Culine $\mathrm{S}$ et al. Update on the medical treatment of metastatic renal cell carcinoma. Eur Urol 2008; 54:315-25

3 Crow $\mathrm{P}$, Stone N, Kendall CA et al. The use of Raman spectroscopy to identify and grade prostatic adenocarcinoma in vitro. Br J Cancer 2003; 89:106-8

4 Crow P, Uff JS, Farmer JA, Wright MP, Stone N. The use of Raman spectroscopy to identify and characterize transitional cell carcinoma in vitro. BJU Int 2004; 93:1232-6

5 Bensalah K, Fleureau J, Rolland D et al. Raman spectroscopy: a novel experimental approach to evaluating renal tumours. Eur Urol 2010; 58:602-8

6 Bensalah K, Peswani D, Tuncel A et al. Optical reflectance spectroscopy to differentiate benign from malignant renal tumours at surgery. Urology 2009; 73:178-81

7 Bensalah K, Tuncel A, Peshwani D, Zeltser I, Liu H, Cadeddu J. Optical reflectance spectroscopy to differentiate renal tumour from normal parenchyma. J Urol 2008; 179:2010-3

8 Fleureau J, Bensalah K, Rolland D et al. Characterization of renal tumours based on Raman spectra classification. Expert Syst Appl 2011; 38:14301-6

9 Lacombe F, Lavastre O, Senhadji L. Early diagnosis of human colorectal cancer. IRBM 2011; 32:83-6 
10 Vapnik V. The Nature of Statistical Learning Theory . Berlin : Springer-Verlag, 1995

$11 \mathrm{Liu}$ CH, Das BB, Sha Glassman WL et al. Raman, fluorescence, and time-resolved light scattering as optical diagnostic techniques to separate diseased and normal biomedical media. J Photochem Photobiol B 1992; 16:187-209

12 Richards-Kortum R, Rava RP, Petras RE, Fitzmaurice M, Sivak M, Feld MS. Spectroscopic diagnosis of colonic dysplasia . Photochem Photobiol 1991; 53:777-86

13 Toms SA, Konrad PE, Lin WC, Weil RJ. Neuro-oncological applications of optical spectroscopy. Technol Cancer Res Treat 2006; 5:231-8

14 Chwirot BW, Chwirot S, Sypniewska N et al. Fluorescence in situ detection of human cutaneous melanoma: study of diagnostic parameters of the method. J Invest Dermatol 2001; 117:1449-51

15 Alfano RR, Das BB, Cleary J, Prudente R, Celmer EJ. Light sheds light on cancer - distinguishing malignant tumours from benign tissues and tumours. Bull N Y Acad Med 1991; 67:143-50

16 Canetta E, Mazilu M, De Luca AC et al. Modulated Raman spectroscopy for enhanced identification of bladder tumour cells in urine samples. J Biomed Opt 2011; 16:037002

17 Crow P, Molckovsky A, Stone N, Uff J, Wilson B, WongKeeSong LM. Assessment of fiberoptic nearinfrared raman spectroscopy for diagnosis of bladder and prostate cancer. Urology 2005; 65:1126-30

18 de Jong BW, Schut TC, Maquelin K et al. Discrimination between nontumour bladder tissue and tumour by Raman spectroscopy. Anal Chem 2006; 78:7761-9

19 Draga RO, Grimbergen MC, Vijverberg PL et al. In vivo bladder cancer diagnosis by high-volume Raman spectroscopy. Anal Chem 2010; 82:5993-9

20 Parekh DJ, Lin WC, Herrell SD. Optical spectroscopy characteristics can differentiate benign and malignant renal tissues: a potentially useful modality. J Urol 2005; 174:1754-8

21 Shapiro A, Gofrit ON, Pizov G, Cohen JK, Maier J. Raman molecular imaging: a novel spectroscopic technique for diagnosis of bladder cancer in urine specimens. Eur Urol 2011; 59:106-12

22 Stone N, Hart Prieto MC, Crow P, Uff J, Ritchie AW. The use of Raman spectroscopy to provide an estimation of the gross biochemistry associated with urological pathologies. Anal Bioanal Chem 2007; 387:1657-68

23 Cheville JC, Lohse CM, Zincke H, Weaver AL, Blute ML. Comparisons of outcome and prognostic features among histologic subtypes of renal cell carcinoma. Am J Surg Pathol 2003; 27:612-24

24 Pan CC, Chen PC, Chiang H. Overexpression of KIT (CD117) in chromophobe renal cell carcinoma and renal oncocytoma. Am J Clin Pathol 2004; 121:878-83

25 Waldert $\mathrm{M}$, Klatte $\mathrm{T}$, Haitel A et al. Hybrid renal cell carcinomas containing histopathologic features of chromophobe renal cell carcinomas and oncocytomas have excellent oncologic outcomes. Eur Urol 2010; 57:661-5

26 Schmidbauer J, Remzi M, Memarsadeghi M et al. Diagnostic accuracy of computed tomography- 
guided percutaneous biopsy of renal masses. Eur Urol 2008; 53:1003-11

27 Neuzillet Y, Lechevallier E, Andre M, Daniel L, Nahon O, Coulange C. Follow-up of renal oncocytoma diagnosed by percutaneous tumour biopsy. Urology 2005; 66:1181-5

28 Oosterwijk E, Rathmell WK, Junker K et al. Basic research in kidney cancer. Eur Urol 2011; 60:62233

29 Lang $\mathrm{H}$, Lindner $\mathrm{V}$, de Fromont $\mathrm{M}$ et al. Multicenter determination of optimal interobserver agreement using the Fuhrman grading system for renal cell carcinoma: assessment of 241 patients with > 15-year follow-up. Cancer 2005; 103:625-9

30 Beck AH, Sangoi AR, Leung $S$ et al. Systematic analysis of breast cancer morphology uncovers stromal features associated with survival. Sci Transl Med 2011; 3:108ra13

\section{Correspondence:}

Jean-Philippe Couapel, CHU Pontchaillou, Department of Urology, 2 rue Henri Le Guilloux, 35000 Rennes, France.

e-mail: couapel.jp@numericable.fr

Abbreviations: ORS, optical reflectance spectroscopy; OS, optical spectroscopy; RCC, renal cell carcinoma; SVM, support vector machine; RS, Raman spectroscopy.
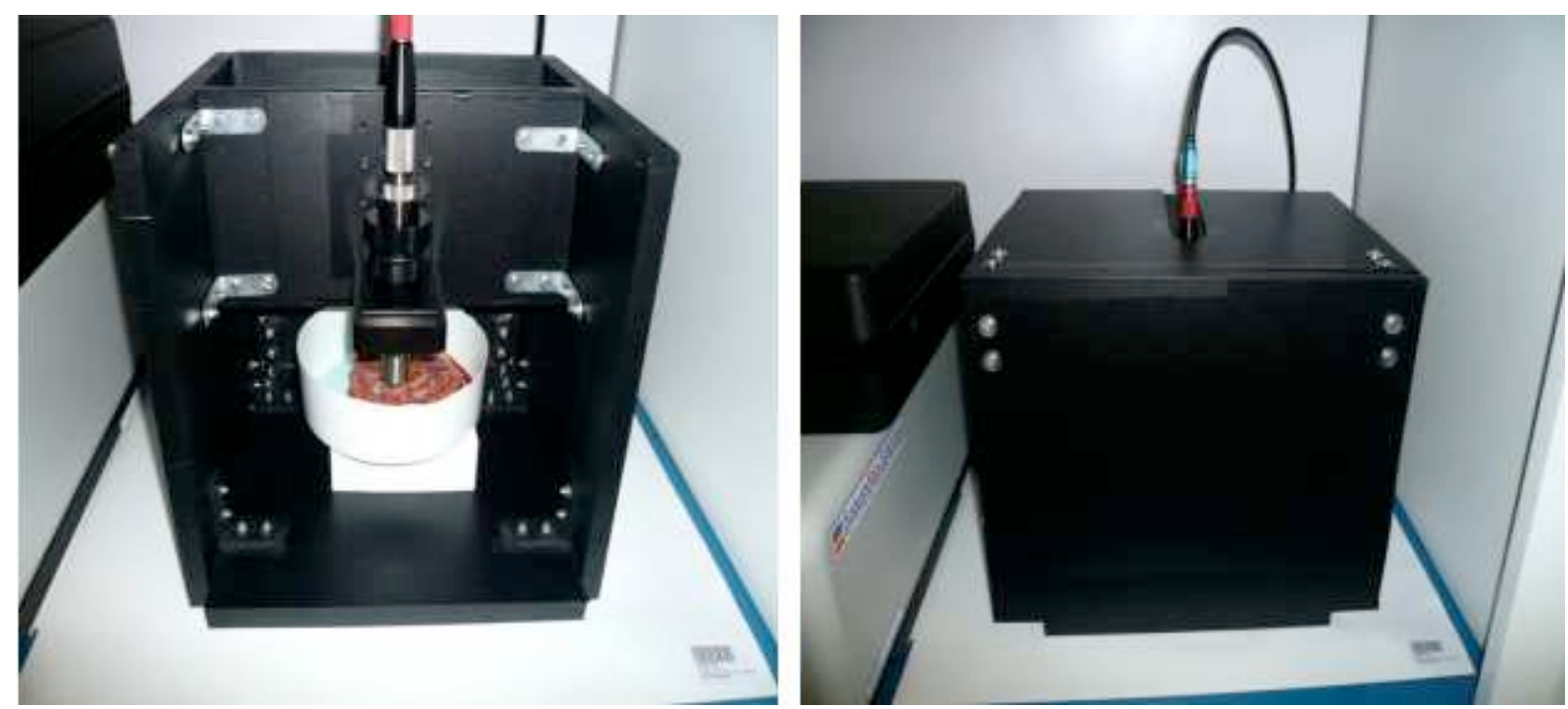

Figure 1: Optical Spectroscopy acquisition device: tumoral kidney is placed under the light source and the spectra are acquired with the black box completely sealed to avoid signal contamination by ambient light. 

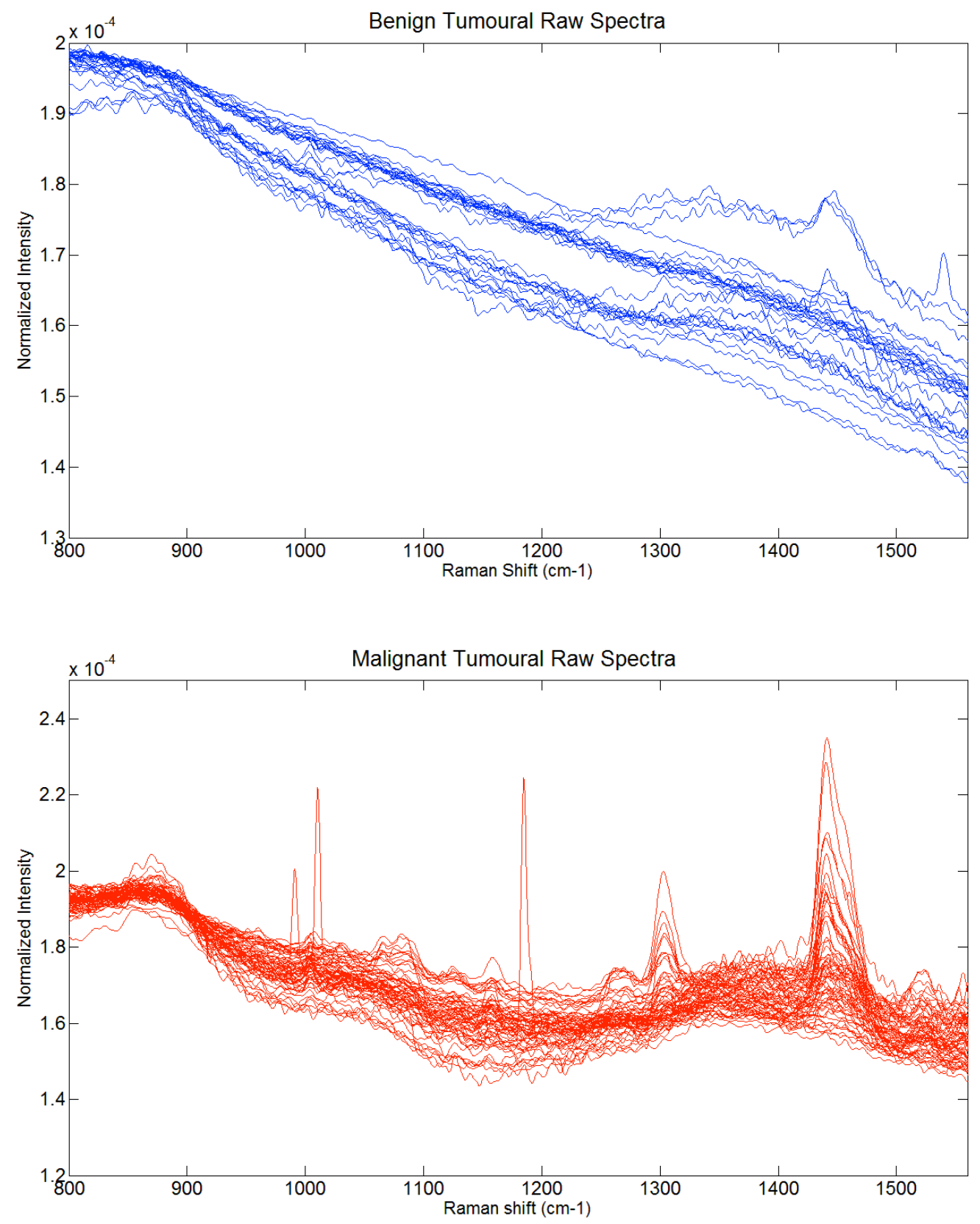

Figure 2: Raman spectra of benign (blue) and malignant tumoral (red) renal tissue. 


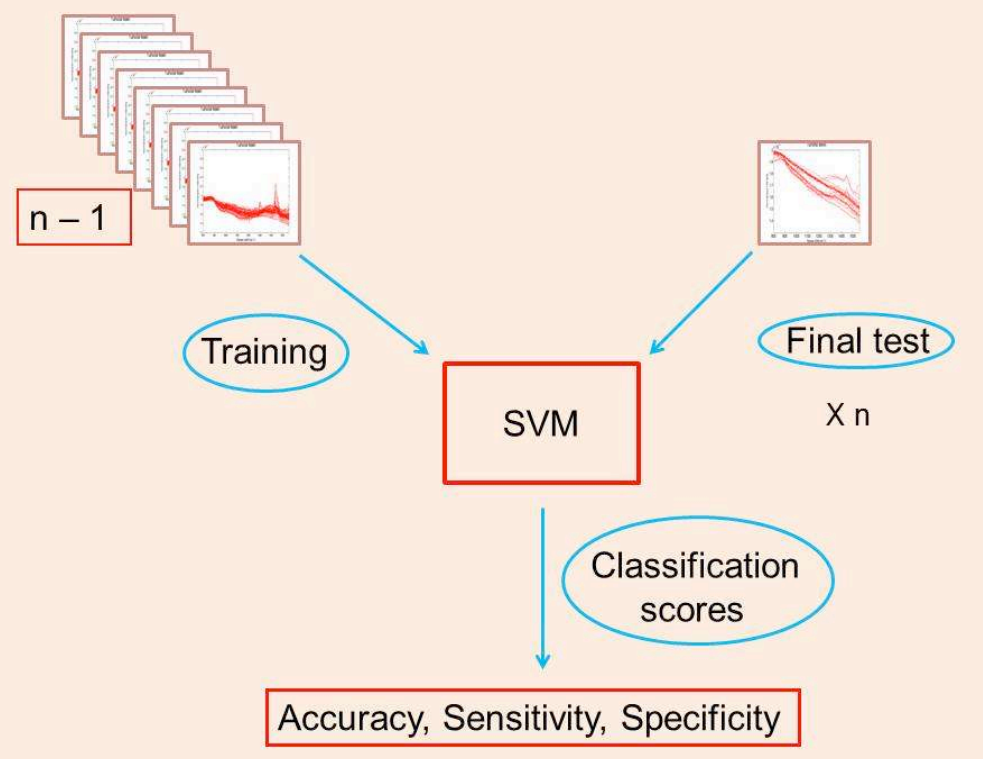

Figure 3: Support Vector Machine illustration. 
Table 1: Patients and tumors characteristics.

\begin{tabular}{|c|c|}
\hline No. of patients & 60 \\
\hline Mean age +/- SD (years) & $61,3 \pm 12,3$ \\
\hline Mean tumor size \pm SD $(\mathrm{cm})$ & $6,1 \pm 3,7$ \\
\hline \multicolumn{2}{|l|}{ Type of surgery, No. } \\
\hline \multicolumn{2}{|l|}{ Radical nephrectomy } \\
\hline Open & 12 \\
\hline Laparoscopic & 21 \\
\hline \multicolumn{2}{|l|}{ Partial nephrectomy } \\
\hline Open & 4 \\
\hline Robotic & 23 \\
\hline \multicolumn{2}{|l|}{ Pathology } \\
\hline Benign & 7 \\
\hline Malignant & 53 \\
\hline \multicolumn{2}{|c|}{ Histologic subtype of malignant tumors } \\
\hline Clear-cell carcinoma & 41 \\
\hline Papillary & 8 \\
\hline Chromophobe & 4 \\
\hline \multicolumn{2}{|l|}{ Tumor stage, No. } \\
\hline pT1a & 19 \\
\hline pT1b & 4 \\
\hline pT2 & 5 \\
\hline pT3 & 23 \\
\hline pT4 & 2 \\
\hline \multicolumn{2}{|l|}{ Nodal invasion, No. } \\
\hline $\mathrm{Nx}-0$ & 52 \\
\hline N1 & 1 \\
\hline \multicolumn{2}{|l|}{ Distant metastases, No. } \\
\hline M0 & 46 \\
\hline M1 & 7 \\
\hline \multicolumn{2}{|l|}{ Tumor grade, No. } \\
\hline Low & 22 \\
\hline High & 31 \\
\hline
\end{tabular}


Table 2: Patients and tumors characteristics for small renal masses $(<4 \mathrm{~cm})$.

\begin{tabular}{|c|c|}
\hline No. of specimens & 28 \\
\hline Mean patient age \pm SD (years) & $60,5 \pm 12$ \\
\hline Mean tumor size \pm SD $(\mathrm{cm})$ & $3 \pm 0,9$ \\
\hline \multicolumn{2}{|l|}{ Type of surgery } \\
\hline \multicolumn{2}{|l|}{ Radical nephrectomy } \\
\hline Open & 1 \\
\hline Laparoscopic & 5 \\
\hline \multicolumn{2}{|l|}{ Partial nephrectomy } \\
\hline Open & 3 \\
\hline Robotic & 19 \\
\hline \multicolumn{2}{|l|}{ Pathology } \\
\hline Benign & 4 \\
\hline Malignant & 24 \\
\hline \multicolumn{2}{|c|}{ Histologic subtype of malignant tumors } \\
\hline Clear-cell carcinoma & 16 \\
\hline Papillary & 5 \\
\hline Chromophobe & 3 \\
\hline \multicolumn{2}{|l|}{ Tumor stage, No. } \\
\hline pT1a & 20 \\
\hline pT1b & 1 \\
\hline pT2 & 0 \\
\hline pT3 & 3 \\
\hline \multicolumn{2}{|l|}{ Tumor grade, No. } \\
\hline Low & 15 \\
\hline High & 9 \\
\hline
\end{tabular}


Table 3: RS and ORS classification scores for the whole population.

\begin{tabular}{|c|c|c|c|c|c|c|c|}
\hline & \multicolumn{3}{|c|}{ Raman } & & \multicolumn{3}{c|}{ Reflectance } \\
\hline & $\begin{array}{c}\text { Accuracy } \\
(\%)\end{array}$ & $\begin{array}{c}\text { Se } \\
(\%)\end{array}$ & $\begin{array}{c}\text { Sp } \\
(\%)\end{array}$ & & $\begin{array}{c}\text { Accuracy } \\
(\%)\end{array}$ & $\begin{array}{c}\text { Se } \\
(\%)\end{array}$ & $\begin{array}{c}\text { Sp } \\
(\%)\end{array}$ \\
\hline $\begin{array}{c}\text { Benign vs } \\
\text { malignant }\end{array}$ & 96,5 & 99,1 & 93,9 & & 87,8 & 95,6 & 80 \\
\hline $\begin{array}{c}\text { Clear cell vs } \\
\text { others }\end{array}$ & 88,3 & 86,4 & 90,2 & & 89,1 & 84,1 & 94,1 \\
\hline $\begin{array}{c}\text { Papillary vs } \\
\text { others }\end{array}$ & 80,6 & 85,9 & 75,2 & & 88,2 & 91,2 & 85,2 \\
\hline $\begin{array}{c}\text { Chromophobe } \\
\text { vs others }\end{array}$ & 92,9 & 95,3 & 90,6 & & 89,7 & 97,9 & 81,6 \\
\hline $\begin{array}{c}\text { Benign vs } \\
\text { Chromophobe }\end{array}$ & 95,9 & 93,5 & 98,2 & & 98,4 & 96,8 & 100 \\
\hline
\end{tabular}

RS = Raman Spectroscopy; ORS = Optical Reflectance Spectroscopy; Se = Sensitivity; $\mathrm{Sp}=$ Specificity 
Table 4: RS and ORS classification scores in small renal masses $(<4 \mathrm{~cm})$.

\begin{tabular}{|c|c|c|c|c|c|c|c|}
\hline & \multicolumn{3}{|c|}{ Raman } & \multicolumn{3}{c|}{ Reflectance } \\
\hline & $\begin{array}{c}\text { Accuracy } \\
(\%)\end{array}$ & $\begin{array}{c}\text { Se } \\
(\%)\end{array}$ & $\begin{array}{c}\text { Sp } \\
(\%)\end{array}$ & $\begin{array}{c}\text { Accuracy } \\
(\%)\end{array}$ & $\begin{array}{c}\text { Se } \\
(\%)\end{array}$ & $\begin{array}{c}\text { Sp } \\
(\%)\end{array}$ \\
\hline $\begin{array}{c}\text { Benign vs } \\
\text { malignant }\end{array}$ & 93,1 & 97,2 & 88,9 & & 95 & 97,9 & 92,1 \\
\hline $\begin{array}{c}\text { Clear cell vs } \\
\text { others }\end{array}$ & 85,4 & 85 & 85,7 & & 94,7 & 92,6 & 96,8 \\
\hline $\begin{array}{c}\text { Papillary vs } \\
\text { others }\end{array}$ & 77,1 & 80 & 74,1 & & 86,7 & 91,7 & 81,7 \\
\hline $\begin{array}{c}\text { Chromophobe } \\
\text { vs others }\end{array}$ & 92,4 & 94,5 & 90,4 & & 88,8 & 96,1 & 81,5 \\
\hline $\begin{array}{c}\text { Benign vs } \\
\text { Chromophobe }\end{array}$ & 87,3 & 85,4 & 89,1 & & 99,6 & 99,3 & 100 \\
\hline
\end{tabular}

RS = Raman Spectroscopy; ORS = Optical Reflectance Spectroscopy; Se = Sensitivity; $\mathrm{Sp}=$ Specificity 